\title{
Legislation ignores benefits of safe injection sites, say doctors
}

A

leading infection-control expert is urging public health officials to speak out about the benefits of safe injection sites instead of staying silent about new federal legislation that will make it harder for communities across Canada to establish new locations.

"There's been a lack of leadership across the board, not just from the federal government," says Dr. Mark Tyndall, chief of the Division of Infectious Diseases at The Ottawa Hospital in Ontario.

"Even local health boards and public health people have not really been vocal in this area. Everybody has just been quite quiet about it, despite overwhelming evidence that this is necessary and that places like Ottawa would greatly benefit from a site like this," says the University of Ottawa professor.

On June 6, Health Minister Leona Aglukkaq introduced Bill C-65, the Respect for Communities Act. The bill requires any organization applying to operate a safe injection site to produce a suite of information that advocates say will make it nearly impossible to get a new site under way. Because possessing and injecting drugs remain criminal activities, harm-reduction sites such as Insite in Vancouver, British Columbia, must apply to the health minister for an exemption to the Controlled Drugs and Substances Act.

"Our government believes that creating a location for sanctioned use of drugs obtained from illicit sources has the potential for great harm in a community," Aglukkaq told a news conference when introducing the bill. She was flanked by the president of the Canadian Police Association. "That's why the proposed legislation includes a strong, local, public consultation component."

Since Parliament has recessed for the summer, the bill will be voted on in the fall session.

The legislation responds to a 2011 Supreme Court decision that ordered the health minister to grant an exemption for Insite, citing its clients' right to

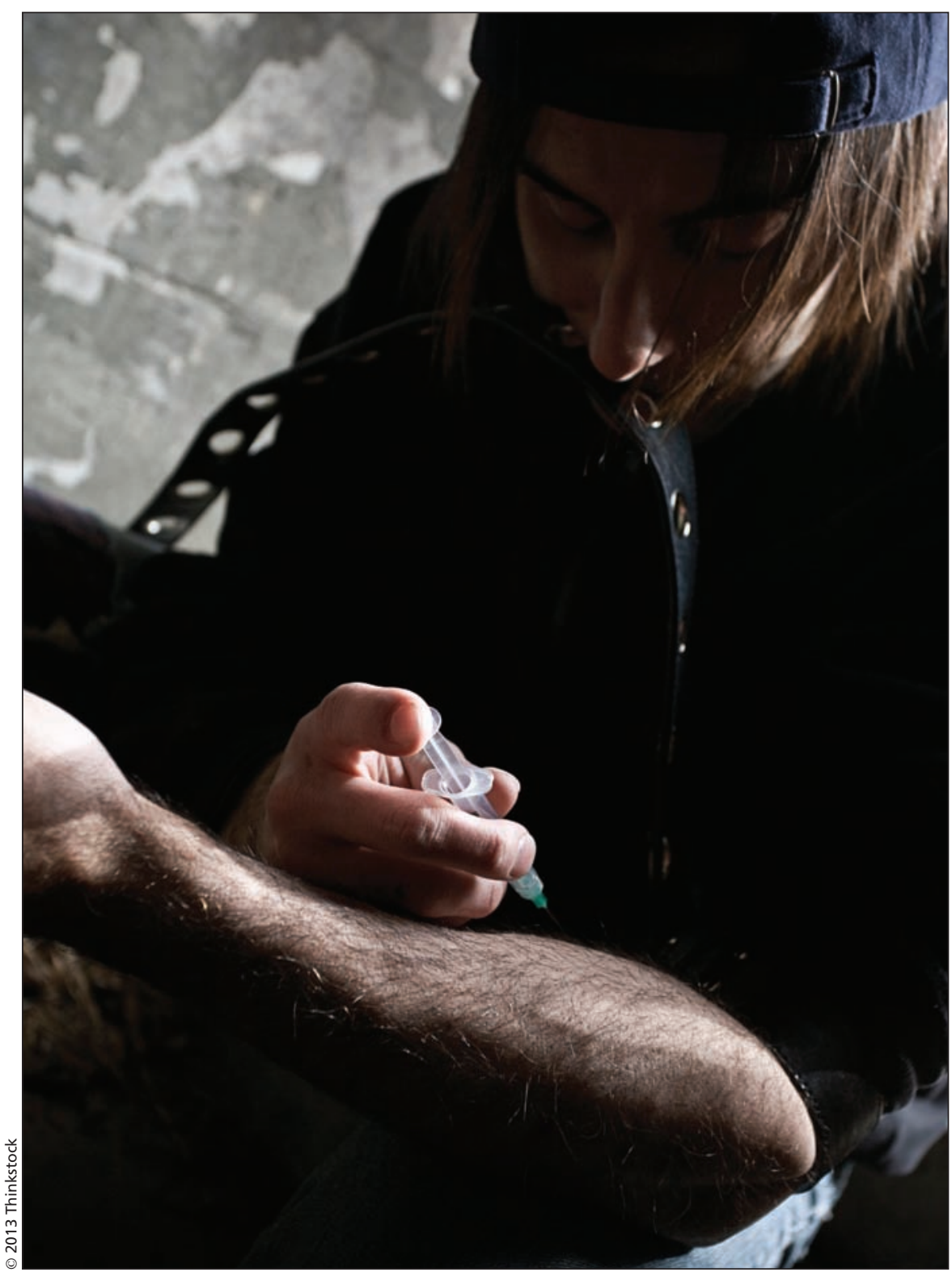

Evidence indicates that safe injection sites address risky injection behaviours that can lead to complications like HIV and hepatitis infections, as well as abscesses and necroses.

life, liberty and "security of the person," and the interests of fundamental justice. The decision directed the minister to balance public health and public safety when weighing future exemptions. The court also directed the minister to generally grant exemptions if there is little or no negative impact on public safety, and if the sites reduce death and disease.
The new legislation goes further than the Supreme Court intended and is ideologically motivated, contends Tyndall and other doctors who point to evidence that harm-reduction strategies reduce HIV, hepatitis and other infections spread through injection drug use.

"There's clear evidence that they [safe injection sites] address risky injection 
behaviours, and that they therefore could potentially lead to decreased complications like HIV and hepatitis infections, as well as abscesses and necroses," says Dr. Ahmed Bayoumi, an internist and researcher at the Centre for Research on Inner City Health at St. Michael's Hospital in Toronto, Ont.

Bayoumi also coauthored the Report of the Toronto and Ottawa Supervised Consumption Assessment Study, 2012, which concluded Toronto could benefit from three supervised injection facilities and Ottawa from two.

A new study by the British Columbia Centre for Excellence in HIV/AIDS supports Tyndall and Bayoumi's claims for the health benefits of safe injection sites. The study indicates Vancouver's harm-reduction strategy, including the Insite location, has reduced illicit drug use, improved public safety and reduced new HIV and hepatitis C infections (www.cmaj.ca /lookup/doi/10.1503/cmaj.109-4528).
There is also good evidence that the centre facilitates entrance into treatment programs for people who are ready to quit using, says Bayoumi.

"This is not legislation that's really focused on health at all," he says of the Respect for Communities Act. "The Supreme Court was clear that the health concerns had to be considered relative to the community concerns. What this legislation does is focus only on those community concerns."

The legislation would require applicants to submit the views of local law enforcement, municipal leaders, public health officials and provincial and territorial ministers of health. They would also have to provide information about the expected impact on local crime rates, data on drug use in the community, treatment options, evidence of sufficient resources to sustain the site and public health reasons for operating it, among other documentation.

The Canadian Medical Association is concerned that these requirements "may be creating unnecessary obstacles and burdens that could ultimately deter creation of more injection sites," it said in a statement. Harm-reduction tools, including supervised injection sites, should be part of a national drug strategy, the CMA said.

"The CMA's position is founded upon clinical evidence. Bill C-65, it would appear, is founded upon ideology that seeks to hinder initiatives to mitigate the very real challenges and great personal harm caused by drug abuse," the statement added.

Despite the obstacles, community organizations in Ottawa, Toronto and in Montréal, Quebec, will likely submit applications to test the new legislation if it is passed, says Tyndall. "We still want to position this as a health intervention in communities that are in a desperate state." - Laura Eggertson, CMAJ

CMAJ 2013. DOI:10.1503/cmaj.109-4536 